\title{
Study of the effect of temperature on the electrical conductivity of aqueous solutions of amino acids
}

\author{
(C) Vera A. Petrukhina, Pavel I. Fedorov, Tatiana A. Kirillova, Ludmila Yu. Tcareva, \\ Ekterina V. Andreeva, and Nikolay I. Koltsov* ${ }^{+}$ \\ Department of Physical Chemistry and Macromolecular Compounds. I.N. Ulyanov Chuvash State University . \\ Moskovsky Ave., 15. Cheboksary, 428015. Chuvash Republic. Russia. \\ Phone: +7 (8352) 45-24-68.E-mail: koltsovni@mail.ru
}

\begin{abstract}
*Supervising author; ${ }^{+}$Corresponding author Keywords: aqueous solutions of amino acids, specific and equivalent electrical conductivity, temperature, Arrhenius equation.
\end{abstract}

\begin{abstract}
It is well-known fact that water is a universal solvent due to its physicochemical properties and dielectric constant. Therefore, the majority of substances with a crystalline structure and the structure close to it are well soluble in water due to the dissociation of molecules into ions. Amino acids are organic ampholytes - substances capable of being in ionic forms in water. The quantitative and qualitative composition of ampholytes depends on the structure and composition of amino acids and $\mathrm{pH}$ of solution. The interaction of amino acid ions in solution with hydrogen ions and hydroxyl leads to the formation of complex cations and anions. The presence of amino and carboxyl groups in amino acid molecules contributes to the formation of inter-ion positively and negatively charged complexes which leads to the decrease in their mobility and electrical conductivity of solutions. It is observed with increasing concentration of amino acid solutions. The conductivity of amino acid solutions is also influenced by temperature which has a non-linear relationship. We have proposed the approach based on studying the effect of temperature on the equivalent electrical conductivity at infinite dilution $\lambda_{\infty}$ and describing the experimental data $\lambda_{\infty}(T)$ by the exponential Arrhenius equation. This article studies the possibility of describing the experimental data $\lambda_{\infty}(T)$ for aqueous solutions of a number of amino acids by this equation. It is shown that the Arrhenius equation with the found activation energy values adequately describes the dependences of limiting equivalent conductivity on temperature for aqueous solutions of valine, leucine, isoleucine, threonine, lysine, methionine, phenylalanine, $L$-aspartic and $D$-aspartic acids, histidine, arginine.
\end{abstract}

\section{References}

[1] Vera A. Petruhina, Tatiana A. Kurnaleva, Daria A. Egorova, and Nikolay I. Koltsov Investigation of the influence of temperature on electrical conductivity of aqueous solutions of electrolytes. Part 1. Strong electrolytes. Butlerov Communications. 2016. Vol.45. No.1. P.107-109. DOI: 10.37952/ROI-jbc-01/1645-1-107

[2] V.A. Petruhina, T.A. Kurnaleva, D.A. Egorova, A.S. Vasileva, and N.I. Koltsov. Investigation of the influence of temperature on electrical conductivity of aqueous solutions of electrolytes. Part 2. Weak electrolytes. Butlerov Communications. 2016. Vol.45. No.1. P.110-112. DOI: 10.37952/ROI-jbc-01/1645-1-102

[3] V.A. Petrukhina, E.V. Andreeva, and N.I. Koltsov. Investigation of the influence of temperature on electrical conductivity of aqueous solutions of electrolytes. Part 3. Nitrates. Butlerov Communications. 2017. Vol.49. No.1. P.104-107. DOI: 10.37952/ROI-jbc-01/17-49-1-104

[4] V.A. Petrukhina, E.V. Andreeva, and N.I. Koltsov. Investigation of the influence of temperature on electrical conductivity of aqueous solutions of electrolytes. Part 4. Acetates and phosphates. Butlerov Communications. 2018. Vol.53. No.2. P.140-144. DOI: 10.37952/ROI-jbc-01/18-53-2-140

[5] E.N. Egorov, N.F. Ushmarin, S.I. Sandalov, I.S. Spiridonov, and N.I. Koltsov. The influence of functional ingredients on the technological properties of oil swelling rubber sealing elements. Butlerov Communications. 2018. Vol.54. No.5. P.159-164. DOI: 10.37952/ROI-jbc-01/18-54-5-159 